\title{
PENINGKATAN KEMAMPUAN BERPIKIR KRITIS MELALUI MODEL AUDITORY, INTELLEKTUALY, REPATITION (AIR) BERBANTUAN KOMIK IPA DI SEKOLAH DASAR
}

\author{
Yunita Sari $^{1}$, Zulela MS $^{2}$, Vina Iasha ${ }^{3}$, Jeane Kalengkongan ${ }^{4}$ \\ ${ }^{1}$ Universitas Islam Sultan Agung Semarang; ${ }^{2,3}$ Universitas Jakarta; ${ }^{4}$ Universitas Negeri Manado, \\ Indonesia \\ Email: vunitasari@unissula.ac.id
}

\section{Info Artikel}

Sejarah Artikel:

Diserahkan 19 Juli 2020

Direvisi 2 November 2020

Direvisi 20 November 2020

Disetujui 21 November 2020

\section{Keywords:}

critical thinking,

auditory intelectualy repatition,

comic science

\begin{abstract}
This study aims to improve critical thinking skills by using Auditory, Intellectually, Repatition (AIR) learning models assisted by science comics.

This research is a Classroom Action Research (CAR). The subjects of the research were the fifth grade students of Beji 03 Public Elementary School, totaling 27 students. Data collection techniques include tests in the form of evaluation questions and non-test techniques, using observation. Data analysis of critical thinking skills using evaluation questions. To calculate the increase in students using a normalized Gain test.

The results obtained by students' critical thinking skills, in the first cycle completeness of $40.74 \%$ and the average achieved by 58.96 then in the second cycle the completeness of students increased to $85.18 \%$ and the average achieved to be 73.70 it can be concluded that the use of the Auditory learning model, Intellectually, Repatition (AIR) assisted by science comics can improve the critical thinking skills of fifth grade students of Beji 03 Elementary School.
\end{abstract}

\footnotetext{
Abstrak

Penelitian ini bertujuan untuk peningkatkan kemampuan berpikir kritis dengan menggunakan model pembelajaran Auditory, Intellectually, Repatition (AIR) berbantuan komik IPA.

Penelitian ini merupakan Penelitian Tindakan Kelas (PTK). Subyek penelitian adalah siswa kelas V SD Negeri Beji 03 yang berjumlah 27 siswa. Teknik pengumpulan data meliputi tes yang berupa soal evaluasi dan teknik non tes, dengan menggunakan observasi. Analisis data kemampuan berfikir kritis dengan menggunakan soal evaluasi. Untuk mengitung peningkatan sisiwa menggunakan uji N-Gain

Hasil penelitian diperoleh kemampuan berfikir kritis siswa, pada siklus I ketuntasan sebesar $40.74 \%$ dan rata-rata yang dicapai sbesar 58.96 kemudian pada siklus II ketuntasan siswa meningkat menjadi $85.18 \%$ dan rata-rata yang dicapai menjadi 73.70 dapat disimpulkan bahwa penggunaan model pembelajaran Auditory, Intellectually, Repatition (AIR) berbantuan komik IPA dapat meningkatkan kemampuan berfikir kritis siswa kelas V SD Negeri Beji 03.
} 
Yunita Sari, Zulela MS, Vina Iasha, Jeane Kalengkongan

PENINGKATAN KEMAMPUAN BERPIKIR KRITIS MELALUI MODEL AUDITORY, INTELLEKTUALY, ...

REFLEKSI EDUKATIKA : Jurnal Ilmiah Kependidikan, Volume 11, Nomor 1, Desember 2020, hlm. 121-126

\section{PENDAHULUAN}

Guru mempunyai peran penting dalam kegiatan belajar mengajar. Dalam kegiatan belajar siswa memperoleh bimbingan dan pengetahuan yang luas, membentuk karakter siswa agar tercipta manusia yang berkualitas guna mencapai cita-cita yang diharapkan. Hal ini sesuai dengan amanat Kurikulum 2013 dimana pembelajaran juga menekankan pada Pendidikan karakter. Perlu diketahui bahwa pembelajaran yang dirancang dalam pendidikan merupakan suatu kegiatan dimana guru membimbing, dan memberikan pengajaran kepada siswa untuk mempelajari suatu informasi yang telah dirancang.

Kegiatan belajar mengajar yang berlangsung di sekolah merupakan interaksi aktif antara siswa dan guru. Guru bukan menjadi pusat dari kegiatan belajar, namun yang lebih penting adalah keterlibatan siswa yang aktif dan penggunaan sumber belajar yang mememadai agar dapat tercipta keselarasan dalam kegiatan belajar. Untuk dapat meningkatkan presetasi siswa agar aktif dan termotivasi dalam kegiatan belajar mengajar, guru dituntut untuk lebih kreatif dalam kegiatan belajar mengajar (Sholekhah, et al., 2019). Pembelajaran yang diharapkan direncanakan oleh seorang guru adalah pembelajaran yan membuat siswa lebih kreatif dapat menumbuhkan sikap ilmiah siswa. Pembelajaran tersbut mampu mengembangkan kemampuan berpikir siswa dengan baik.

Kemampuan berpikir yang sebaiknya dikembangkan dalam proses kegiatan pembelajaran di sekolah dasar adalah kemampuan berpikir tingkat tinggi. Salah satu kemampuan berpikir tingkat tinggi (higher order thinking) adalah kemampuan berpikir kritis (critical thinking). Berpikir kritis sebagai salah satu kompetensi yang ditekankan dalam Kurikulum 2013 (Dewi, et al., 2019). Menurut Yaumi (2012), berpikir kritis merupakan kemampuan kognitif dalam pengambilan kesimpulan berdasarkan alasan logis dan bukti empiris. Pengertian berpikir kritis tersebut diperjelas lagi oleh Eggen dan Don (2012) bahwa pada kegiatan kesimpulan yang dibuat juga cenderung dilakukan asesmen (penilaian) berdasarkan bukti. Johnson (2009) berpendapat bahwa berpikir kritis merupakan sebuah proses yang terarah dan jelas digunakan dalam kegiatan mental seperti memecahkan masalah, mengambil keputusan, membujuk, menganalis asumsi, dan melakukan penelitian ilmiah. Menurut Anderson (Lestari, 2013) bila berpikir kritis dikembangkan, seseorang akan cenderung untuk mencari kebenaran, berpikir divergen (terbuka dan toleran terhadap ide-ide baru), dapat menganalisis masalah dengan baik, berpikir secara sistematis, penuh rasa ingin tahu, dewasa dalam berpikir, dan dapat berpikir secara mandiri. Berdasarkan pendapat ahli tersebut, dapat disimpulkan bahwa kemampuan berpikir kritis merupakan kemampua siswa dalam pemecahan masalah dan pengambilan keputusan (kesimpulan) dari berbagai aspek dan sudut pandang. Kemampuan berpikir kritis merupakan hal yang perlu dimiliki oleh siswa, hal ini agar siswa dapat menghdapi permasalahan-permasalahan yang terjadi dalam kehidupan sehari hari dapat diatasinya.

Permasalahan yang terjadi dilapangan sekarang ini adalah kurangnya pengembangan kemampuan berpikir kritis siswa di tingkat sekolah dasar. Kegiatan pembelajaran yang ada masih dianggap sangat kurang dalam mengembangkan kemampuan berfikir kritis siswa. Berdasarkan observasi dan wawancara yang dilakukan dengan guru kelas 5 SD Negeri Beji 03 Ibu Aliyah, S.Pd, ada beberapa permasalahan yang terjadi antara lain siswa belum mampu mengembangkan penjelasan dari informasi yang diperoleh ketika proses pembelajaran. Hal ini berdampak ketika guru memberikan suatu pertanyaan, siswa kurang dapat memberikan alasan atau pendapatnya berkaitan jawaban yang diberikan. Kurangnya pemahaman siswa dalam memperoleh informasi karena tidak memperhatikan penjelasan dari guru.

Permasalahan lainnya yaitu model pembelajaran yang digunakan oleh guru bersifat konvensional dan cenderung berpusat pada guru, sehingga siswa dalam memperoleh informasi pembelajaran kurang memahami apa yang diajarkan guru. Selain itu bahan ajar yang tersedia di sekolah umumnya berbentuk buku paket dan LKS dengan keterbatasan penyediaan buku paket disekolah membuat siswa kurang semangat dalam pembelajaran. Buku pembelajaran yang ada di sekolah umumnya berupa textbook, meskipun sudah ada variasi penambahan gambar iliustrasi tetapi belum memberikan pengaruh yang cukup terhadap peningkatan minat baca siswa sehingga minat baca menjadi rendah hal ini dapat berpengaruh terhadap kemampuan berfikir kritis siswa.

Berdasarkan data yang diperoleh dari guru kelas 5 Ibu Aliyah, S. Pd bahwa pada pembelajaran tema panas dan perpindahannya semester 2 Tahun Pelajaran 2019/2020 
Yunita Sari, Zulela MS, Vina Iasha, Jeane Kalengkongan

PENINGKATAN KEMAMPUAN BERPIKIR KRITIS MELALUI MODEL AUDITORY, INTELLEKTUALY, ...

REFLEKSI EDUKATIKA : Jurnal Ilmiah Kependidikan, Volume 11, Nomor 1, Desember 2020, hlm. 121-126

penguasaan materi siswa akan muatan IPA rendah. Hal ini dibuktikan dengan jumlah siswa kelas 5 sebanyak 27 siswa yang tidak tuntas sebanyak 16 siswa dengan persentase $59,25 \%$ dan yang tuntas 11 siswa dengan persentase $40,75 \%$. Dengan data yang diperoleh tersebut secara garis besar bahwa selama ini proses pembelajaran muatan IPA di SDN Beji 03 belum sesuai yang diharapkan, kemampuan berpikir kritis siswa ketika pembelajaran masih kurang sehingga mempengaruhi nilai belajar siswa.

Berdasarkan permasalahan tersebut diatas, guru mempunyai peran yang sangat penting dalam mendorong terciptanya proses belajar mengajar secara optimal sehingga siswa dapat belajar secara aktif dan mampu mengembangkan kemampuan berpikir kritis serta penalaran matematis. Namun demikian, kenyataan yang ditemui di lapangan guru masih mengalami kesulitan dalam menyelenggarakan pembelajaran yang efektif (Salim, 2015).

Penggunaan variasi model pembelajaran sangat diperlukan guru dalam pembelajaran agar siswa dapat menerima informasi atau pesan dengan baik, karena melalui model pembelajaran yang bervariasi yang dilakukan guru dapat membantu siswa dalam mendapatkan informasi, ide, keterampilan, dan cara berfikir yang luas. Salah satu model pembelajaran yang dapat diterapkan oleh guru dalam pembelajaran agar tidak membosankan bagi siswa, dan dapat mengembangkan kemampuan berpikir kritis pada siswa adalah menggunakan salah satu model pembelajaran yaitu model pembelajaran Auditory, Intellectually, Repatition (AIR).

Menurut Shoimin (2014) pembelajaran Auditory, Intellectually, Repatition (AIR) merupakan sistem pembelajaran yang efektif apabila memperhatikan tiga hal tersebut. Model pembelajaran AIR merupakan suatu model pembelajaran yang efektif dengan memperhatikan tiga hal, yaitu Auditory, Intellectualy, dan Repatition (AIR). Model pembelajaran AIR menuntut siswa untuk lebih aktif, sedangkan guru sebagai fasilitator siswa dalam belajar. Siswa yang tertarik dengan pembelajaran yang baru akan cenderung lebih antusias dalam mengikuti pembelajaran sehingga kemampuan berpikirnya ketika pembelajaran akan berkembang dan menjadikan siswa lebih tertib dan disiplin ketika belajar (Anwar dan Marudin, 2016).

Penerapan sebuah model dalam kegiatan pembelajaran dapat berlangsung secara maksimal apabila pemilihan bahan ajar yang digunakan juga tepat. Bahar Ajar komik IPA merupakan suatu bahan ajar yang dapat menumbuhkan minat baca, karena mempunyai tampilan yang menarik dengan gambar yang bervariasi sehingga dapat menumbuhkan minat membaca siswa dan membuat kegiatan membaca amat menyenangkan. Komik bukan hanya sekedar media hiburan tetapi komik bisa menjadi media untuk mendidik dan mengajar ilmu pengetahuan dan moral kepada siswa (Purwanto dan Yuliani, 2013).

Sebelumnya telah banyak riset mengenai pembelajaran IPA beserta model pembelajarannya, antara lain oleh Khamdun (2014); Masanah (2016); Rakhma (2016); Suratmi (2016); Wuryanto (2016) dan Malik (2019). Namun riset yang dilakukan memiliki perbedaan dengan penelitian yang sudah ada. Model pembelajaran AIR berbantuan komik IPA yang diterapkan di SDN Bji 03 diharapkan dapat meningkatkan kemampuan berpikir kritis siswa ketika menerima pembelajaran agar dapat mengembangkan pengetahuan yang di perolehnya. Tujuan penelitian ini adalah untuk meningkatkan kemampuan berpikir kritis siswa kelas 5 SDN Beji 03 dengan menggunakan model pembelajaran Auditory, Intellectually, Repatition (AIR) berbantuan komik IPA.

\section{METODE PENELITIAN}

Penelitian ini menggunakan metode penelitian tindakan kelas dengan tujuan memperbaiki atau meningkatkan mutu pembelajaran di kelas melalui suatu tindakan tertentu. Adapun tahap-tahap penelitian ini menurut Lewin (dalam Trianto, 2011) adalah (1) perencanaan, (2) tindakan, (3) observasi, (4) refleksi.

Subjek penelitian ini adalah siswa kelas V SDN Beji 03 yang berjumlah 27 siswa yang terdiri dari 13 siswa laki-laki dan 14 siswa perempuan. Adapun teknik pengumpulan data yang digunakan adalah teknik tes dan non tes. Instrumen tes digunakan untuk mengukur kemampuan berpikir kritis siswa, sedangkan instrument lembar observasi untuk memperoleh data tentang aktivitas guru dan siswa saat pelaksanaan pembelajaran menggunakan model pembelajaran.

Teknik analisis data pada penelitian ini secara deskriptif kuantitatif. Untuk mengetahui peningkatan kemampuan berpikir kritis siswa, maka data hasil tes evaluasi di uji menggunakan uji N-gain. Indikator Keberhasilan adanya peningkatan kemampuan berpikir kritis siswa, 
Yunita Sari, Zulela MS, Vina Iasha, Jeane Kalengkongan

PENINGKATAN KEMAMPUAN BERPIKIR KRITIS MELALUI MODEL AUDITORY, INTELLEKTUALY, ...

REFLEKSI EDUKATIKA : Jurnal Ilmiah Kependidikan, Volume 11, Nomor 1, Desember 2020, hlm. 121-126

sekurang-kurangnya $\quad 80 \% \quad$ seluruh siswa memperoleh nilai $\geq 65$.

\section{HASIL DAN PEMBAHASAN}

Data mengenai kemampuan berpikir kritis siswa diperoleh dari hasil tes keampuan berfikir kitis yang dikerjakan oleh siswa pada akhir siklus. Lembar evaluasi ini dikerjakan setelah proses pembelajaran IPA dengan menggunakan model pembelajaran Auditory, Intellectually, Repetition (AIR) berbantuan komik IPA pada tema panas dan perpindahannya. Rekapitulasi hasil tes kemampuan berpikir kritis siswa pada siklus I disajikan pada Tabel 1 berikut ini.

Tabel 1 Rekapitulasi hasil kemampuan berpikir kritis siswa pada siklus I

\begin{tabular}{lc}
\hline \multicolumn{1}{c}{ Indikator } & Keterangan \\
\hline Jumlah siswa & 27 \\
KKM & 66 \\
Jumlah siswa tuntas belajar & 7 \\
Jumlah siswa tidak tuntas belajar & 20 \\
Jumlah nilai & 1553 \\
Rata-rata nilai & 57.51 \\
Presentse ketuntasan & $25.92 \%$ \\
\hline
\end{tabular}

Berdasarkan tabel diatas, diketahui bahwa hasil tes masih rendah, terbukti dengan masih banyak siswa yang belum memenuhi Kriteria Ketuntasan Minimal (KKM) yaitu 66. Hasil menunjukan bahwa nilai rata-rata kelas masih dibawah nilai KKM yaitu 57.51. Persentase ketuntasan kelas hanya $25.92 \%$ dengan nilai terendah 40 dan nilai tertinggi 73. Berdasarkan hasil pada siklus I, maka dilakukan perbaikan pembelajaran pada siklus II. Adapaun rekapituasi hasil tes kemampuan berpikir kritis siswa pada siklus II disajikan dalam Tabel 2.

Tabel 2 Rekapitulasi hasil kemampuan berpikir kritis siswa pada siklus II

\begin{tabular}{lc}
\hline \multicolumn{1}{c}{ Indikator } & Keterangan \\
\hline Jumlah siswa & 27 \\
KKM & 66 \\
Jumlah siswa tuntas belajar & 23 \\
Jumlah siswa tidak tuntas belajar & 4 \\
Jumlah nilai & 1990 \\
Rata-rata nilai & 73.70 \\
Presentse ketuntasan & $86.18 \%$ \\
\hline
\end{tabular}

Hasil tes kemampuan berpikir kritis siswa pada siklus II sudah memenuhi indicator keberhasilan. Tabel 2 menunjukan bahwa nilai rata-rata kelas sebesar 73.70 dengan ketuntasan belajar $85.18 \%$. Berdasarkan data tersebut, terjadi peningkatan kemampuan berpikir kritis siswa dari siklus I ke siklus II.
Peningkatan hasil tes kemampuan berpikir kritis siswa, dikarenakan penerapan model AIR berbantuan komik IPA. Hal ini sejalan dengan penelitian yang dilakukan oleh Ain dan Kamaluddin (2019) adanya pengaruh model pembelajaran Auditory Intellectually Repetition (AIR) dalam meningkatkan kemampuan berpikir kritis siswa kelas X MAN Poso Pesisir. Hal ini didukung karena adanya perbedaan kemampuan berpikir kritis antara siswa yang diberi model pembelajaran Auditory Intelectualy Repetition (AIR) dengan siswa yang diterapkan model pembelajran konvensional. serta di perkuat oleh pendapat Meier dalam penelitian (Elinawati, et al., 2017) yang menyatakan bahwa pikiran auditoris lebih kuat dari pada yang kita sadari. Telinga kita terus menerus menangkap dan menyimpan informasi bahkan tanpa kita sadari.

Untuk mengetahui peningkatan hasil tes kemampuan berpikir kritis secara statistic, maka dilakukan Uji N-gain. Uji Hasil uji N-gain dapat dilihat pada Tabel 3 .

Tabel 3 Uji N-gain peningkatan ketuntasan

\begin{tabular}{lcc}
\hline Kriteria & Ketuntasan & Uji N-gain \\
\hline Siklus I & $25.92 \%$ & Skor Fostes - Skor Pretes \\
Siklus II & $85.18 \%$ & Skor ideal - skor pretes
\end{tabular}

\begin{tabular}{ll}
\hline Nilai N-gain & 0.79 \\
\hline
\end{tabular}

Hasil pengitungan uji Gain diperoleh peningkatan sebesar 0.79 interprestasi Gain ternormalisasi termasuk kriteria tinggi. Hasi tersebut sejalan dengan hasil penelitian yang dilakukan Rini (2014) bahwa proses pembelajaran menggunakan model pembelajaran AIR dapat meningkatkan hasil belajar siswa. Penelitian serupa juga dilakukan oleh Fauji dan Winarti (2015) dan diketahui bahwa model pembelajaran Auditory, Intellectually, Repatition (AIR) dapat meningkatkan keterampilan berpikir kritis dan hasil belajar siswa. Dewi, et al., (2019) menambahkan bahwa keaktifan siswa dalam pembelajaran dapat meningkatkan keterampilan berpikir siswa dan sikap ilmiah siswa dalam kegiatan pembelajaran.

Hasil penelitian tersebut menunjukkan bahwa aktivitas siswa meningkat dengan kriteria baik pada siklus I menjadi sangat baik pada siklus II. Sejalan dengan Kawi, et al., (2019) bahwa model pembelajaran auditory, Intellectually and repetition (AIR) yang bertujuan membuat siswa lebih aktif dalam belajar, termotivasi untuk memberikan pembuktian dan penjelasan yang mereka dapat. Selain itu juga, dengan repetition (pengulangan) 
Yunita Sari, Zulela MS, Vina Iasha, Jeane Kalengkongan

PENINGKATAN KEMAMPUAN BERPIKIR KRITIS MELALUI MODEL AUDITORY, INTELLEKTUALY, ...

REFLEKSI EDUKATIKA : Jurnal Ilmiah Kependidikan, Volume 11, Nomor 1, Desember 2020, hlm. 121-126

membuat pelajaran yang diberikan akan lebih lama membekas dalam ingatan siswa dibandingkan dengan pembelajaran yang tidak memiliki tahapan repetition (pengulangan)

\section{SIMPULAN}

Pembelajaran dengan menggunakan model pembelajaran Auditory, Intellectualy, Repatition (AIR) dapat meningkatkan kemampuan berpikir kritis siswa. Peningkatan kemampuan berpikir kritis siswa dapat dilihat dari ketuntasan belajar siswa pada siklus I dengan nilai rata-rata 57,21 , dengan presentase ketuntasan sebesar 25,92\%. Sedangkan pada siklus II meningkat dengan nilai rata-rata 73,70 dan persentase ketuntasan sebesar 86,18\%. Hasil uji N-gain menunjukkan terjadi peningkatan yang ternomalisasi sebesar 0,79 dengan interpretasi tinggi.

\section{DAFTAR PUSTAKA}

Ain, N., dam Kamaluddin, K. 2019. Pengaruh Model Pembelajaran Auditory Intellectually Repetition (AIR) terhadap Kemampuan Berpikir Kritis Siswa Kelas $\mathrm{X}$ MAN Poso Pesisir. JPFT (Jurnal Pendidikan Fisika Tadulako Online), 8 (2).

Anwar, K., dan Marudin. 2016. Penerapan Model Pembelajaran Auditory, Intellectualy, Repetition (AIR) untuk Meningkatkan Hasil Belajar Siswa Kelas IV pada Mata Pelajaran PKn di SDN 11 Mataram. ẽl-Midad Jurnal Jurusan PGMI, 10 (1): 26-40.

Dewi, A.S., Purbasari, Imaniar., dan Khamdun. 2019. Pengaruh Model Think Pair Share terhadap Kemampuan Berpikir Kritis Siswa Tema Pahlawanku Kelas I SD Unggulan Muslimat NU. Jurnal Prakarsa Paedagogia, 2 (1): 67-75.

Dewi, S.A.P.P.C., Fakhriyah, Fina., dan Purbasari, Imaniar. 2019. Peningkatan Sikap Ilmiah Siswa melalui Guided Inquiry Berbantuan Media Papan Putar Pada Tema Pahlawanku Kelas IV. Jurnal Prakarsa Paedagogia, 2 (2): 198-203.

Eggen, Paul dan Don Kauchak. 2012. Strategi dan Model Pembelajaran Mengajarkan
Konten dan Keterampilan Berpikir. Jakarta: Indeks.

Elinawati, W., Duda, H. J., dan Julung, H. 2018. Penerapan Model Pembelajaran Auditory Intellectually Repetition (AIR) terhadap Hasil Belajar Kognitif Siswa. Sainsmat: Jurnal Ilmiah Ilmu Pengetahuan Alam, 7 (1): 13-24.

Fauji dan Winarti. 2015. Meningkatkan Keterampilan Berpikir Kritis Dan Hasil Belajar Siswa Melalui Model Pembelajaran Auditory, Intellectually, Repetition (AIR) Pada Materi Hidrolisis Garam di Kelas XI IPA 2 SMA PGRI 6 Banjarmasin. Jurnal Inovasi Pendidikan Sains.

Johnson, E. 2009. Contextual Teaching and Learnin, Menjadikan Kegiatan Belajar Mengajar Mengasyikan dan Bermakna. Bandung: Kaifa.

Kawi, K.A.Y., I Nengah Suadnyana, dan IB Surya Manuaba. 2019. Pengaruh Model Pembelajaran Auditory, Intellectualy, Repetition Berbantuan Media Audio Visual terhadap Kompetensi Pengetahuan IPA, International Journal of Elementary Education, 3 (1): 70-78.

Khamdun. 2014. Peningkatkan Hasil Belajar IPA Melalui Inkuiri Terbimbing Pada Siswa SDN I Ngembalrejo Bae Kudus. REFLEKSI EDUKATIKA : Jurnal Ilmiah Kependidikan, 4 (2).

Lestari, K.E., 2013. Implementasi Brain Based Learning untuk Meningkatkan Kemampuan Koneksi dan Kemampuan Berpikir Kritis Matematis Siswa Sekolah Menengah Pertama. (Tesis). Sekolah Pascasarjana, UPI Bandung.

Malik, Jamaludin. 2019. Penerapan Metode Diskusi Kelompok Untuk Meningkatkan Hasil Belajar IPA Dan Aktivitas Siswa Kelas IV SD I Sidorekso Pada Materi Menggolongkan Hewan Berdasarkan Jenis Makanannya. REFLEKSI EDUKATIKA : Jurnal Ilmiah Kependidikan, 9 (2): 128-133. 
Yunita Sari, Zulela MS, Vina Iasha, Jeane Kalengkongan

PENINGKATAN KEMAMPUAN BERPIKIR KRITIS MELALUI MODEL AUDITORY, INTELLEKTUALY, ...

REFLEKSI EDUKATIKA : Jurnal Ilmiah Kependidikan, Volume 11, Nomor 1, Desember 2020, hlm. 121-126

Masanah. 2016. Peningkatan Hasil Belajar IPA Materi Tumbuhan Hijau Melalui Metode Eksperimen Kelas V SDN Babadan Semester 1 Tahun Pelajaran 2015/2016. REFLEKSI EDUKATIKA : Jurnal Ilmiah Kependidikan, 7 (1): 22-26.

Purwanto, D., dan Yuliani. 2013. Pengembangan Media Komik IPA Terpadu Tema Pencemaran Air Sebagai Media Pembelajaran untuk Siswa SMP Kelas VII. Jurnal Pendidikan Sains e-Pensa. 1 (1): 71-76.

Rakhma, Ifa Seftia., Widyaningsih, Unik., dan Mawartiningsih, Lilik. 2016. Pengembangan Magic Crossword Puzzle Sebagai Media Pembelajaran IPA Untuk Siswa Kelas V Sekolah Dasar. REFLEKSI EDUKATIKA : Jurnal Ilmiah Kependidikan, 7 (1): 69-77.

Rini, D. V. 2014. Penerapan Model Pembelajaran Air (Auditory Intellectually Repetition) Untuk Meningkatkan Hasil Belajar Siswa Pada Pembelajaran Tematik Kelas IV A SD Negeri 02 Tulung Balak Tahun Pelajaran 2013/2014. Disertasi.

Salim Nahdi, D. 2015. Meningkatkan kemampuan berpikir kritis dan penalaran matematis siswa melalui model brain based learning. Jurnal Cakrawala Pendas, 1 (1): 266-386.
Shoimin. 2014. Model Pembelajaran Inovatif dalam Kurikulum 2013. Yogyakarta: ArRuzza Media.

Sholekhah, K., Roysa, Mila., dan Masfuah, Siti. 2019. Penerapan Model Mind Mapping Berbantuan Media Pohon Ajaib Pada Siswa Tema 6 Cita-Citaku Kelas IV Sekolah Dasar. Jurnal Prakarsa Paedagogia, 2 (2): 213-229.

Suratmi. 2016. Meningkatkan Prestasi Belajar IPA Dengan Menerapkan Metode Student Teams Achievement Divisions Berbantuan CD Pembelajaran Pada Siswa Kelas IV Semester 1 Di SD N Karangtowo. REFLEKSI EDUKATIKA : Jurnal Ilmiah Kependidikan, 7 (1): 1-10.

Trianto. 2008. Mendesain Pembelajaran Kontekstual (Contextual Teaching and Learning) di Kelas. Jakarta: Cerdas Pustaka Publisher.

Wuryanto. 2016. Meningkatkan Prestasi Belajar IPA Dengan Media Video Dan Metode Stad Semester 1 Kelas IV SDN Babadan Tahun 2015/2016. REFLEKSI EDUKATIKA : Jurnal Ilmiah Kependidikan, 6 (2).

Yaumi, Muhammad. 2012. Pembelajaran Berbasis Multiple Intelligences. Jakarta: Dian Rakyat. 